\title{
MODELO DE MADUREZ COMO BASE PARA EL DIAGNÓSTICO DE LA GESTIÓN DE PROCESOS PYME
}

\section{MATURITY MODEL AS FOUNDATIONS OF A SME PROCESS MANAGEMENT DIAGNOSIS}

\author{
Claudia Rohvein ${ }^{1,}$, Mario Jaureguiberry² , Silvia Urrutia ${ }^{3}$, Geraldina Roark ${ }^{4}$, \\ Franco Chiodi $^{5}$, Diana Paravie ${ }^{6}$
}

\section{RESUMEN}

La gestión de procesos de negocio y sus modelos de madurez están recibiendo especial interés académico como herramienta para evaluar procesos, reconocer dónde y cómo avanzar y mejorar el uso de recursos. En un ambiente complejo como el actual, las PYME Argentinas pueden recurrir a elevar la madurez de sus sistemas de gestión de procesos como medio para apoyar su desarrollo empresarial y confrontar la inestabilidad del contexto. El modelo de madurez de procesos de negocios propuesto por Fisher proporciona un balance entre una representación simple y un suficiente grado de detalle para ser usado en PYME.

En la presente investigación se utiliza dicho modelo para obtener un diagnóstico en tres casos de estudio PYME y confirmar la hipótesis planteada donde se afirma que las organizaciones certificadas bajo Norma ISO 9001:2015 obtienen mayores niveles de madurez en su sistema de gestión de proceso de negocios. La prueba estadística de comparación de medias comprobó que existe diferencia significativa entre las organizaciones, confirmando la hipótesis. Se concluye que los factores de éxito de la gestión por procesos establecida y el uso de modelos de madurez de procesos de negocios integrados a sistemas de gestión bajo normas de calidad son beneficiosos.

Palabras clave: Sistema de gestión de procesos, modelo de madurez de procesos de negocios de Fisher, modelo de madurez, PYME, ISO 9001, Argentina.

\footnotetext{
${ }^{1}$ Dpto. Ingeniería Industrial, Facultad de Ingeniería, Universidad Nacional del Centro de la Provincia de Buenos Aires, Olavarría, Argentina. orcid.org/0000-0002-0159-5806 ${ }^{2}$ Dpto. Ingeniería Industrial, Facultad de Ingeniería, Universidad Nacional del Centro de la Provincia de Buenos Aires, Olavarría, Argentina. orcid.org/0000-0002-8929-8872 ${ }^{3}$ Dpto. Ingeniería Industrial, Facultad de Ingeniería, Universidad Nacional del Centro de la Provincia de Buenos Aires, Olavarría, Argentina. orcid.org/0000-0002-5862-0048 ${ }^{4}$ Dpto. Ingeniería Industrial, Facultad de Ingeniería, Universidad Nacional del Centro de la Provincia de Buenos Aires, Olavarría, Argentina. orcid.org/0000-0002-4430-9873 ${ }^{5}$ Dpto. Ingeniería Industrial, Facultad de Ingeniería, Universidad Nacional del Centro de la Provincia de Buenos Aires, Olavarría, Argentina.orcid.org/0000-0001-6874-3888 ${ }^{6}$ Dpto. Ingeniería Industrial, Facultad de Ingeniería, Universidad Nacional del Centro de la Provincia de Buenos Aires, Olavarría, Argentina. orcid.org/0000-0002-4597-7726
}

-Autor para correspondencia: crohvein@fio.unicen.edu.ar 


\section{ABSTRACT}

Business process management and maturity models are receiving special academic interest as a key tool for evaluating, recognizing where and how to move forward, improving resource use, and achieving distinctive capabilities. In the actual complex and dynamic environment, SMEs can resort to raising the maturity of their process management systems as a means to support their business development and confront context instability with internal strengthening. The business process maturity model proposed by Fisher provides a balance between a simple representation and a sufficient degree of detail for use in SME.

This research uses this model to obtain a diagnosis in three case studies and confirm the hypotheses raised where it is stated that organizations certified under ISO 9001:2015 obtain higher levels of maturity in their process management system. A statistical test of comparison of means found significant differences between companies, confirming the hypothesis. It is concluded that the success factors of process management established and the use of business process maturity models integrated into management systems under quality standards are useful.

Keywords: Process management system BPMM-Fisher, maturity models, ISO 9001, SME, Argentina.

\section{INTRODUCCIÓN}

Las pequeñas y medianas empresas (PYME) del sector industrial desempeñan un papel destacado en la economía Argentina, al representar el segmento productivo que emplea al $70 \%$ de los ocupados del país. No obstante, la principal dificultad de las PYME Argentinas en la actualidad se relaciona con sus altos costos productivos frente a una prolongación del escenario recesivo, consecuente cierre de empresas nacionales y el incremento en el nivel de competencia debido a la aparición de importaciones (Fundación Observatorio PYME, 2019a; CAME, 2017).

Por otro lado, la turbulencia cambiaria y la elevada incertidumbre actual, truncaron el pequeño repunte que la actividad de la industria manufacturera PYME había experimentado a principios de 2019 , donde la confianza en la evolución económica presente y futura había mejorado y anunciaba un potencial repunte en la inversión (Fundación Observatorio PYME, 2019b).

De la encuesta realizada en 2019 a la PYME, se informa que sólo el $34 \%$ de las mismas ha accedido al crédito debido principalmente a las altas tasas de interés de financiación. Además, para afrontar los desafíos del próximo año y avanzar en los procesos de transformación digital y desarrollo de nuevos negocios, las PYME están evaluando utilizar sus propios recursos y profundizar la reducción de sus costos de estructura (PwC Argentina, 2019). 
Argentina necesita un marco de mayor previsibilidad a largo plazo pero, ¿qué pueden hacer las PYME para no esperar todo del Estado para desarrollarse?, ¿cómo generar fortalezas que le otorguen ventajas competitivas?. Para afrontar grandes desafíos los recursos son los activos de una organización, los cuales sustentan sus fortalezas. No sólo es necesario dotar de recursos tangibles e intangibles, sino explotar una profunda interacción entre ellos para avanzar sobre capacidades distintivas (Wheelen \& Hunger, 2007). Ante este contexto, donde las PYME Argentinas son relevantes por su impacto social a nivel empleo, es vital encontrar herramientas para contribuir a mejorar su nivel de eficiencia en el uso de recursos. En efecto, lograr fortalecimiento interno, para enfrentar las continuas amenazas del medio externo ya sean variables políticas y/o económicas.

Resultados de la investigación de Lockamy III y McCormack (2004) han demostrado que la orientación hacia los procesos de negocios (BPO) es esencial para fomentar una mayor conexión dentro de la organización y mejorar su performance. La aplicación de los elementos del BPO son clave al momento de implementar mejoras, como una vista de procesos horizontal, su gestión, medición y responsabilidad inter funcional. En los últimos años la atención a los procesos de negocios ha aumentado y las organizaciones están trabajando en la implementación de acciones para mejorarlos. Sin embargo, su desarrollo es gradual dando lugar entonces, a ésta noción de madurez como una medida para indicar cuán excelente es el desempeño de un proceso. La gestión y mejora de los procesos de negocio, ha sido una tarea central del desarrollo organizacional. Por ello, los modelos de madurez están recibiendo un marcado crecimiento de interés investigativo (Röglinger et al., 2012).

La madurez se ha estudiado desde el punto de vista de los sistemas de gestión de calidad, programas de excelencia y a partir del concepto de Bussiness Process Managment (BPM). (Díaz Jaimes \& Ortiz Pimiento, 2013). En Trkman (2010) se ha definido al BPM como aquellos esfuerzos que una organización realiza en sus actividades clave para analizarlas y mejorar los elementos importantes relacionados con la operación de la empresa.

En general, un modelo de madurez es una herramienta para evaluar y mejorar habilidades, capacidades y competencias (Moradi Moghadam et al., 2013). En Siqueira (2005) se ha señalado que el concepto básico detrás de la palabra madurez, es que organizaciones maduras realizan sus actividades a partir de procesos sistematizados y métodos documentados, mientras que los procesos y los métodos inmaduros varían de acuerdo a los individuos que realizan las tareas. Por lo tanto, teniendo en cuenta que en las organizaciones maduras los datos se recogen y se utilizan con el fin de analizar el control, la previsión y el rendimiento de la planificación, estas organizaciones alcanzan sus objetivos de calidad, tiempo y costo de una manera coherente y eficaz. Contrariamente, las organizaciones inmaduras no alcanzan sus objetivos, la calidad lograda no es lo que esperaban, los plazos son superiores a los planificados y los costos exceden a los presupuestados.

Para Duffy (2001) el valor de un modelo de madurez radica en su uso como herramienta de análisis y posicionamiento, ya que busca ayudar a las organizaciones a reconocer cuándo y por qué deben avanzar, proporcionándoles una visión de las medidas que deben adoptarse.

Deacuerdo con Lahti et al. (2009), el término madurez traduce el desarrollo de una etapa inicial a una etapa final en la que hay una evolución de procesos de etapa intermedia, a la plena madurez. Cuando se aplica en el contexto de los procesos de negocio, alcanzar la madurez significa conseguir un nivel de excelencia y mejora continua con el fin de mantener la alineación de la dinámica del mercado, especialmente como resultado de la evolución tecnológica y la expansión de los medios de comunicación.

Complementariamente en Tarhan et al. (2016), se ha estudiado el grado de avance de la 
bibliografía sobre los modelos de madurez. Para ello, basaron su búsqueda entre los años 1990 y 2014 para identificar los estudios centrándose en su desarrollo, validación y aplicación. Los autores concluyen que la literatura académica carece de aplicaciones metódicas de muchos modelos que se han propuesto. Agregan, que un modelo de madurez puede ser una referencia efectiva para iniciativas de mejora de procesos. Aunque existe un amplio conjunto de modelos de madurez para el campo BPM, su uso en la práctica es limitado. Las evaluaciones empíricas de los modelos de madurez de BPM son realmente escasas, ya que los modelos son diseñados principalmente para fines descriptivos de uso. Sugieren, que trabajos futuros deben incluir la realización de encuestas a la industria para obtener más conocimiento de los factores que contribuyen u obstaculizan el uso y el éxito de los modelos de madurez de negocios en la práctica,

Fryt (2019) concluye que tanto los principios básicos como los principios descriptivos de los modelos de madurez de procesos, están suficientemente abordados. Sin embargo, hay margen de mejora con respecto a descripciones más detalladas de la aplicación relevante de criterios de evaluación fáciles de usar. En lo que respecta al propósito normativo de la aplicación, se pueden identificar pocas pautas específicas y documentadas. Esto significa que aquellos que aplican el modelo de madurez enfrentan dificultades cuando buscan medidas apropiadas para mejorar sus procesos. Recomienda realizar encuestas entre empresas orientadas a procesos para permitir un análisis cuantitativo y explicativo. El autor cree que los datos cualitativos confirmarán la utilidad de la gestión por procesos.

Navarro et al. (2018) han analizado que la concentración de la producción científica, sobre sistemas de gestión de procesos de negocio en determinados países, autores y universidades ponen de manifiesto el estado embrionario de la investigación en este tópico en el área de gestión y, más específicamente, en el área de organización de empresa. Por ello, han indicado que es preciso promover este campo de investigación internacionalmente, para generar estudios empíricos globales sobre BPM que permitan una comparativa internacional $y$, de este modo, se propicie el avance contrastado de los conocimientos teóricos y prácticos sobre este tipo de sistemas.

En un ambiente complejo y dinámico como el actual, las PYME deben involucrarse en un proceso de mejora de sus sistemas de gestión de procesos para apoyar el desarrollo empresarial a través de la disponibilidad de información relevante, que permita desarrollar una gestión proactiva (Röglinger et al., 2012).

Páez et al. (2018), han realizado una comparación entre modelos de madurez, centrados en los procesos de negocios y gestión con enfoque de procesos. Para determinar la factibilidad de uso en PYME, los modelos se han analizado a través de criterios: dominio de aplicación, propósito de uso, cantidad de dimensiones, cantidad de niveles, descripción por niveles, procedimiento de aplicación, estilo de representación gráfica y complejidad de uso. Del análisis se ha deducido que los modelos de Fisher (2004) y la Norma ISO 9004, reflejan ser los más indicados para utilizar en PYME, debido principalmente a su baja complejidad de uso. Su dominio de aplicación es genérico, su propósito de uso descriptivo pero no disponen de un procedimiento de aplicación. Por tanto al momento de utilizarlo se debe armar un instrumento que ayude a realizar el diagnóstico y complementar con una metodología de evaluación. Asimismo, al definir acciones para transitar la ruta de mejoramiento, se debe especificar cómo identificar los niveles de madurez deseables y proporcionar directrices sobre medidas de mejora. Por su parte, los modelos CCMI y EFQM disponen de un procedimiento de aplicación pero su complejidad de uso es mayor. 
se descompone en cinco componentes que representan el núcleo de la mayoría de las organizaciones. A éstas se las denomina "cinco palancas de cambio", y se designan como estrategia, procesos, tecnología, control y gente. La segunda dimensión son los estados de madurez de estas palancas de cambio. En el modelo, la dimensión "cinco palancas de cambio" proporciona los componentes sobre los cuales se puede evaluar las capacidades de una organización en particular. A medida que las capacidades avanzan, la compañía puede progresar a través de la segunda dimensión del modelo, esto es, los estados de madurez. Estos estados se representan por niveles, siendo estos denominados por el propio autor del modelo como: nivel 1 (Aislado), nivel 2 (Tácticamente integrado), nivel 3 (Proceso conducido), nivel 4 (Empresa optimizada) y nivel 5 (Red inteligente de operaciones).

Como aspectos positivos el modelo presenta una estructura simple y fácil de comprender. Es un modelo no lineal y multidimensional, con palancas de cambio mutuamente dependientes que proporcionan dirección sobre los aspectos a mejorar prioritariamente para lograr una madurez organizacional superior. Considera la integración externa en su último nivel, rasgo que lo distingue de otros modelos.

Consecuentemente, se decide utilizar el modelo de Fisher (2004), para diagnosticar la madurez del sistema de gestión de los procesos y aportar al desempeño de las PYME. Sin embargo, algunas organizaciones Argentinas hacen uso de las Normas ISO 9001 para certificar su sistema de calidad las cuales se rigen por un enfoque de procesos, por lo cual surge la pregunta ¿empresas con un sistema de gestión de calidad implementado y certificado contarán con un sistema de gestión de procesos de negocios más maduros que aquellas que no lo dispongan?, ¿la orientación a procesos es fundamental para lograr procesos maduros?.

La PYME en Argentina que posee alguna certificación de calidad segmento del Centro (zona que comprende los partidos de la provincia de Buenos Aires y las provincias de Córdoba, Entre Ríos y Santa $\mathrm{Fe}$ ) es de $17 \%$ para las ISO y $10 \%$ para otro tipo de certificaciones, siendo el mismo porcentaje para las ISO a nivel nación y 9\% para las otras (Fundación Observatorio PYME, 2015). En Olavarría, ciudad perteneciente al sector Centro y lugar de influencia de la facultad donde se enmarca el proyecto de investigación, las organizaciones han avanzado lentamente en la certificación de sistemas de normas correspondiente a calidad ISO 9001:2015, seguridad OHSAS 18001:2015 y medioambiente ISO 14001:2015.

La literatura adiciona que la gestión por proceso debe acompañarse con mediciones acertadas, uso de indicadores confiables y representativos, apoyados en la tecnología y uso de la tecnología de la información (TI). Finalmente confirman los factores de éxito de BPO establecido y el uso de modelos de madurez de procesos de negocios integrados a los sistemas de gestión de procesos estandarizados bajo normas.

Se plantea como hipótesis: que las organizaciones con un sistema de gestión de calidad implementado y certificado bajo Norma ISO 9001:2015 obtienen mayores niveles de madurez en su sistema de gestión de procesos de negocios.

\section{MATERIAL Y MÉTODOS}

La metodología que se utilizó para realizar la investigación sobre la madurez del sistema de gestión de los procesos de negocios consistió en el estudio de caso propuesto por Yin 
(2014). En la presente investigación se realizaron tres estudios de caso donde se estudió un fenómeno organizacional que involucra diversas variables que no son sencillas de analizar y este enfoque ayuda a utilizar la experiencia para la transmisión del conocimiento.

Con base en la definición de Yin (2014) sobre un estudio de caso se realizó una investigación empírica que estudió la gestión de los procesos de negocios dentro del contexto empresarial. Se trató su situación involucrando más de una variable de interés y basándose en múltiples fuentes de evidencia, con el beneficio del desarrollo previo de proposiciones teóricas que guiaron la recolección y el análisis de datos que convergieron en un estilo de triangulación.

Estos estudios de caso son descriptivos para identificar el nivel de madurez de las dimensiones que caracterizan el sistema de gestión de procesos de negocios, según el modelo de madurez propuesto por Fisher (2004). El modelo de madurez de procesos de negocio (BPMM) de Fisher (2004) se presenta como una herramienta capaz de proporcionar un balance entre una representación simple que cualquier persona pueda entender fácilmente y un modelo que contenga el suficiente grado de detalle como para proveer ideas que conduzcan a acciones específicas a utilizar por las organizaciones que deseen mejorar su desempeño, (Anexo 1).

El modelo de Fisher, 2004 es representado en dos dimensiones, hecho que aporta una menor complejidad en su cantidad de ejes y establece la cuadricula donde se enmarcan los detalles del propio modelo y se encuentran las descripciones de cada nivel para cada uno de los aspectos a evaluar. Esta cuadricula se ha utilizado para especificar el nivel de desempeño actual por medio de un diagnóstico gráfico que mostró la ruta de mejoramiento. Se ha comenzado por los sectores con menor valor de desempeño para interpretar la ruta a seleccionar.

Para efectuar la elección de las unidades de análisis se definieron como principales criterios: el tamaño de la empresa, el tipo de actividad, la certificación o avance en desarrollo de sistemas de normas de calidad, seguridad y medioambiente, grado de accesibilidad y la ubicación.

Los tres casos de estudio escogidos se eligieron usando los criterios citados y radican en la ciudad de Olavarría, Provincia de Buenos Aires - Argentina. Se optó por esta ubicación por ser el lugar de influencia de la facultad donde se enmarca el proyecto de investigación. De este modo se logró contar con la representación de un caso que no usa ningún sistema de normas, otro que cuenta con certificación en al menos un sistema, y finalmente otro con certificación en un sistema y con un mediano avance en la aplicación de los otros sistemas de normas.

La selección de tales casos de estudio representó la base para evaluar la hipótesis planteada, donde se espera que las organizaciones con un sistema de gestión de calidad implementado y certificado bajo la Norma ISO 9001:2015 alcancen mayores niveles de madurez en su sistema de gestión de procesos de negocios. La prueba de hipótesis evaluada esta descrita en la Ecuación 1:

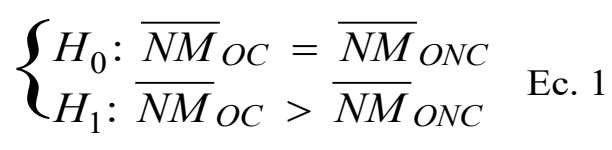


Siendo:

- $\overline{N M}_{O C}$ : La media del nivel de madurez de procesos en organizaciones certificadas bajo Norma ISO 9001:2015.

- $\overline{N M}_{\text {ONC }}$ : La media del nivel de madurez de procesos en organizaciones no certificadas bajo Norma ISO 9001:2015.

Esta prueba de hipótesis correspondió a una diferencia de medias para muestras independientes, la cual se resolvió a través del software Infostat 2016, para corroborar si existe o no una diferencia significativa en la variable "nivel de madurez" respecto a la existencia o no de una certificación de calidad en las organizaciones caso de estudio.

La primera unidad de análisis seleccionada fue una PYME con un plantel de 50 personas que se dedica al diseño y producción de calefactores, hornos, cocinas, parrillas, termotanques y calderas a leña, sistemas de calefacción central por aire y serpentina de agua caliente. Sus clientes se ubican geográficamente a nivel nacional. No posee avance alguno en la aplicación de los principios de los sistemas de normas. La accesibilidad es buena, en cuanto a entrevistas realizadas, pero baja en referencia a datos principalmente por motivo que no cuentan con registro alguno.

La segunda unidad de análisis seleccionada fue una PYME industrial metalmecánica con un plantel de 80 personas y presencia en el mercado por más de 40 años que se dedica principalmente al diseño y fabricación de productos de metal, puesta en marcha de equipamientos industriales metalmecánicos y electrónicos y al mantenimiento de equipos industriales, en Argentina y Latinoamérica. Actualmente cuenta con certificación ISO 9001:2015. Ante la consulta, esta empresa ha manifestado su disponibilidad y accesibilidad para brindar información al equipo de investigación.

La tercera unidad de análisis seleccionada fue una PYME metalmecánica que realiza actividades de diseño y fabricación de productos de metal y puesta en marcha de equipamientos industriales metalmecánicos. La diversidad de productos ofrecidos va desde estructura pesada hasta liviana, pero con una ponderación mayor en la primera. Ofrecen desde una instalación de estructura metálica pesada en obras de minerías hasta construcción de domos o galpones. Su mercado está en Argentina con expansión a Brasil y Uruguay. Sus clientes son principalmente la industria cementera, minera y cerealera. Su estructura en recursos humanos está conformada por 120 empleados. En cuanto a los sistemas de normas han certificado el correspondiente a calidad ISO 9001:2015, se encuentra en desarrollo el de seguridad y en menor grado de avance el de medioambiente. La accesibilidad es valiosa y relevante.

La recolección de datos surgió de fuentes primarias mediante la realización de entrevistas semiestructuradas a directores, gerentes y empleados, con una guía de preguntas elaborada en pos de responder a la caracterización de cada dimensión y su nivel de madurez, (Anexo 2).

La información recopilada se analizó sobre la base de transcripciones literales de la entrevista, posterior agrupación de comentarios en cada eje de análisis y observaciones por campo temático de manera de responder a la caracterización de cada dimensión. Finalmente, para determinar el nivel de madurez alcanzado se comparó con las descripciones provistas en 
el modelo de Fisher (2004) para cada dimensión y nivel de madurez detalladas en el Anexo 1. Se estableció, dividir en dos etapas de avance cada nivel, de modo que si no alcanza totalmente las condiciones de un nivel dado, se posiciona al $50 \%$ de el y se valora con 0,5 .

\section{RESULTADOS Y DISCUSIÓN}

El análisis de la información recopilada en las entrevistas realizadas en cada caso de estudio a los actores clave de las PYME seleccionadas (con soporte en el Anexo 2) arrojó diferentes niveles de madurez del sistema de gestión de procesos en cada una de las cinco palancas de cambio para cada caso de estudio, Figura 1.

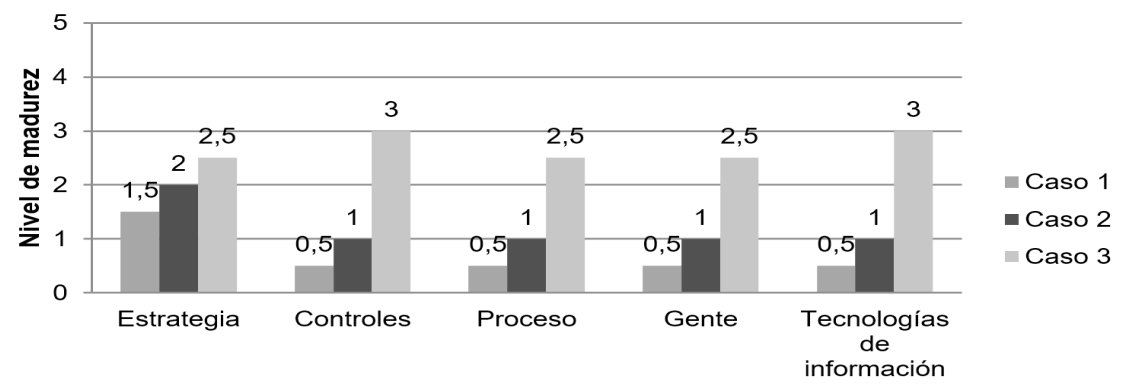

Figura 1. Nivel de madurez del sistema de gestión de procesos de cada empresa caso de estudio.

En la Tabla 1 se brinda un detalle en cada dimensión con datos y citas textuales, que justifican la determinación del nivel de madurez para cada palanca de cambio planteada en el modelo de Fisher (2004), (Anexo 1). 


\section{Tabla 1. Información recopilada en cada dimensión analizada en base al modelo de madurez de Fisher (2004).}

\begin{tabular}{|c|c|c|c|}
\hline Dimensiones & Caso 1 & Caso 2 & Caso 3 \\
\hline Estrategia & $\begin{array}{l}\text { La misión y visión no están definidas, } \\
\text { como tampoco están formalizados } \\
\text { los objetivos estratégicos. En pala- } \\
\text { bras del Gerente general "persiguen } \\
\text { vender } 1500 \text { estufas por mes". Como } \\
\text { la estrategia es emergente, no hay } \\
\text { una frecuencia definida para revisar } \\
\text { planes estratégicos. Consecuente- } \\
\text { mente no hay vinculación formali- } \\
\text { zada entre estrategia de negocios y } \\
\text { funcional porque la primera no está } \\
\text { definida y nadie se involucra en su } \\
\text { implementación. } \\
\text { Sin embargo tienen diversidad de } \\
\text { productos e innovación en el dise- } \\
\text { ño y han crecido mucho en infraes- } \\
\text { tructura. Se expandieron geográfi- } \\
\text { camente logrando un crecimiento } \\
\text { con clientes a nivel nacional. Sin el } \\
\text { acompañamiento de mejoras en su } \\
\text { gestión. } \\
\text { Al momento de la entrevista la em- } \\
\text { presa se encontraba en el desarrollo } \\
\text { innovador de una estufa con alimen- } \\
\text { tación a pellet. De dicha entrevista se } \\
\text { evidencia que el dueño de la empre- } \\
\text { sa tiene características de un empre- } \\
\text { sario innovador con buenas ideas de } \\
\text { productos. } \\
\text { Por otro lado no desarrolla integra- } \\
\text { ción con los proveedores, no plan- } \\
\text { tea formalidad alguna para resolver } \\
\text { problemas. Tampoco posee un orga- } \\
\text { nigrama claro y definido, solamente } \\
\text { nombra área de producción, admi- } \\
\text { nistración y comercialización. } \\
\text { Asimismo, se vislumbra que su es- } \\
\text { trategia está basada en el liderazgo } \\
\text { en costos. Según el Gerente general } \\
\text { "Tiene el precio más bajo del merca- } \\
\text { do, con una excelente relación pre- } \\
\text { cio/calidad". }\end{array}$ & $\begin{array}{l}\text { La gerencia general realiza una re- } \\
\text { visión anual de estrategias respe- } \\
\text { tando la exigencia de la ISO } 9001 . \\
\text { Al momento de detectar un proble- } \\
\text { ma con un producto en la planta, } \\
\text { se resuelve con las personas in- } \\
\text { volucradas, ya sea el responsable } \\
\text { de calidad, ingeniería, RRHH, pro- } \\
\text { ducción, u otros involucrados. Sin } \\
\text { embargo, cuando el producto llega } \\
\text { al cliente participa únicamente el } \\
\text { Gerente General y el cliente. } \\
\text { De forma similar, cuando existe } \\
\text { algún tipo de problema con un ser- } \\
\text { vicio de mantenimiento o montaje, } \\
\text { interviene el Gerente General en } \\
\text { comunicación directa con el cliente. } \\
\text { El Gerente General manifestó "que } \\
\text { usualmente confía únicamente en } \\
\text { sí mismo para resolver problemas } \\
\text { con los clientes externos". } \\
\text { En cuanto a los proveedores, la } \\
\text { empresa efectúa una clasificación } \\
\text { binaria en función de la criticidad } \\
\text { para el proceso. Con la mayoría de } \\
\text { los insumos considerados críticos } \\
\text { se establece una relación de inte- } \\
\text { gración con el proveedor. }\end{array}$ & $\begin{array}{l}\text { Aunque la misión y visión están formuladas, no han sido } \\
\text { consensuadas ni compartidas con el personal. } \\
\text { La estrategia es deliberada sólo por el dueño de la em- } \\
\text { presa, pero no se comparte. Su visión es convertirse en } \\
\text { la empresa metalúrgica más grande del país. } \\
\text { Tienen diversidad de productos, estructura pesada, } \\
\text { mediana y liviana. Su mercado es la instalación de es- } \\
\text { tructura metálica pesadas en las obras de ingeniería. La } \\
\text { empresa se expande muy rápidamente. Geográficamen- } \\
\text { te atiende a nivel nacional y ha incursionado reciente- } \\
\text { mente en Brasil y Uruguay. Adicionalmente, cuenta con } \\
\text { una persona específica en el área comercial, que busca } \\
\text { nuevos clientes. } \\
\text { No hay vinculación formalizada entre la estrategia de } \\
\text { negocios y las funcionales, ya que la primera no está } \\
\text { escrita ni comunicada. Dado que sólo la dirección la co- } \\
\text { noce, nadie puede involucrarse en su implementación. } \\
\text { Aunque no posee un organigrama claro y definido, existe } \\
\text { cierto grado de integración interfuncional por medio de } \\
\text { reuniones semanales con responsables de cada área } \\
\text { (oficina técnica, compras, administración, recursos hu- } \\
\text { manos, calidad, dirección, producción) para afrontar los } \\
\text { problemas que van surgiendo. La compra de un siste- } \\
\text { ma TI de gestión llamado Strumis que integra todas las } \\
\text { áreas y es de uso exclusivo para las estructuras metáli- } \\
\text { cas, le da a la empresa en análisis una ventaja competi- } \\
\text { tiva frente a sus competidores. La empresa se anticipa al } \\
\text { uso de tecnologías y es seguido por sus competidores. } \\
\text { Su ventaja competitiva se vincula con su flexibilidad ha- } \\
\text { cia el cliente, respondiendo a sus demandas rápidamen- } \\
\text { te, sin medir el impacto en el funcionamiento de la em- } \\
\text { presa. La integración con proveedores no es estrecha ni } \\
\text { cercana en cambio con los clientes sí. } \\
\text { En palabras del jefe de producción "La empresa ha co- } \\
\text { brado una gran dimensión, su crecimiento ha sido de } \\
\text { expansión muy rápida y aún hoy mantiene las informa- } \\
\text { lidades de una PYME. Actualmente, se ha incorporado } \\
\text { una profesional en el área de recursos humanos para } \\
\text { formalizar muchos aspectos, entre ellos la identidad de } \\
\text { la empresa y el desarrollo de carrera del personal". }\end{array}$ \\
\hline
\end{tabular}




\begin{tabular}{|c|c|c|c|}
\hline Controles & $\begin{array}{l}\text { No presenta una estructura jerárqui- } \\
\text { ca formal y la toma de decisiones } \\
\text { está centralizada en el dueño y en } \\
\text { el encargado de planta. Asimismo, } \\
\text { no están establecidas responsabi- } \\
\text { lidades y la interacción entre áreas } \\
\text { es sumamente informal. Sólo se rea- } \\
\text { lizan algunas reuniones ocasionales } \\
\text { entre las áreas ante alguna una si- } \\
\text { tuación particular. } \\
\text { Al momento de adquirir un siste- } \\
\text { ma TI, Tango } 17 \text {, no se tuvieron en } \\
\text { cuenta requisitos para la compra. Su } \\
\text { implementación es reciente y no se } \\
\text { usan sistemáticamente los indica- } \\
\text { dores que genera este sistema. Se } \\
\text { observa durante la entrevista que } \\
\text { aún se desconocen los tipos de in- } \\
\text { dicadores que genera dicho sistema. }\end{array}$ & $\begin{array}{l}\text { Se evidencia una estructura jerár- } \\
\text { quica formalmente definida me- } \\
\text { diante un organigrama que la em- } \\
\text { presa expuso durante la visita, pero } \\
\text { no se hace uso del mismo en la } \\
\text { toma de decisiones, sino que ésta } \\
\text { última se encuentra centralizada en } \\
\text { la Gerencia General y en la Geren- } \\
\text { cia Industrial. } \\
\text { En cuanto a los sistemas de TI, se- } \\
\text { gún manifiesta el Gerente General, } \\
\text { se utilizan tres softwares, a través } \\
\text { de los módulos de contabilidad, } \\
\text { administración, compras, depósito, } \\
\text { producción y mantenimiento. } \\
\text { Se pudo comprobar, durante la } \\
\text { entrevista, que no existen procedi- } \\
\text { mientos escritos que den normati- } \\
\text { vas para el uso de estos sistemas } \\
\text { de TI ni tampoco se realiza una } \\
\text { evaluación del valor que agregan } \\
\text { los mismos a la gestión de la em- } \\
\text { presa. } \\
\text { Respecto al enfoque de procesos, } \\
\text { se pudo observar que si bien existe } \\
\text { un mapa de procesos, éste sólo se } \\
\text { ha elaborado para cumplir con un } \\
\text { requisito de la Norma ISO } 9001 \text { (si- } \\
\text { tuación que fue validada por el res- } \\
\text { ponsable de la Gerencia Industrial). } \\
\text { Mediante el análisis de la informa- } \\
\text { ción recolectada, existe una depar- } \\
\text { tamentalización por funciones, no } \\
\text { hay evidencias de una interrelación } \\
\text { directa ni comunicación formal en- } \\
\text { tre éstas, sino que más bien la Ge- } \\
\text { rencia General establece vínculos } \\
\text { uno a uno con cada función. } \\
\text { Aspecto a destacar es el descono- } \\
\text { cimiento de los clientes y provee- } \\
\text { dores internos en los procesos de } \\
\text { la empresa. }\end{array}$ & $\begin{array}{l}\text { La toma de decisiones resulta parcialmente descentrali- } \\
\text { zada, el dueño delega autoridad en niveles medios. Este } \\
\text { nivel presenta poco interacción con otras áreas. No está } \\
\text { delimitada la responsabilidad de cada uno. } \\
\text { Si bien no existen procedimientos formales que esta- } \\
\text { blezcan requisitos de compra, forma de uso y alcance de } \\
\text { las TI, se prioriza el uso de sistemas que integren áreas, } \\
\text { muestren indicadores de avances, puedan utilizarse en } \\
\text { conjunto con otros sistemas de manera vinculada y mar- } \\
\text { quen la trazabilidad de los productos fabricados. }\end{array}$ \\
\hline Procesos & $\begin{array}{l}\text { Las actividades se realizan de forma } \\
\text { aislada, sin TI como soporte. Los } \\
\text { principales insumos son chapa y } \\
\text { vidrio, contando con proveedores } \\
\text { fuertes que imponen sus condicio- } \\
\text { nes. No obstante no desarrollan } \\
\text { vínculo estrecho con proveedores. } \\
\text { Asimismo, no aplican programas de } \\
\text { mejora continua, resultando mejoras } \\
\text { totalmente reactiva. Finalmente, se } \\
\text { evidencia una incipiente trazabilidad } \\
\text { del producto. }\end{array}$ & $\begin{array}{l}\text { Respecto al enfoque de procesos, } \\
\text { se pudo observar que si bien } \\
\text { existe un mapa de procesos, éste } \\
\text { sólo se ha elaborado para cumplir } \\
\text { con un requisito de la Norma ISO } \\
9001 \text { (situación que fue validada } \\
\text { por el responsable de la Gerencia } \\
\text { Industrial). } \\
\text { Mediante el análisis de la informa- } \\
\text { ción recolectada, existe una depar- } \\
\text { tamentalización por funciones, no } \\
\text { hay evidencias de una interrelación } \\
\text { directa ni comunicación formal } \\
\text { entre éstas, sino que más bien la } \\
\text { Gerencia General establece víncu- } \\
\text { los uno a uno con cada función. } \\
\text { Aspecto a destacar es el descono- } \\
\text { cimiento de los clientes y provee- } \\
\text { dores internos en los procesos de } \\
\text { la empresa. }\end{array}$ & $\begin{array}{l}\text { Si bien trabajan con las exigencias de un sistema de } \\
\text { gestión de calidad según Norma ISO } 9001 \text { aún no se } \\
\text { han implementado todas las acciones del enfoque de } \\
\text { procesos. En este sentido, faltan definir responsabili- } \\
\text { dades e interacciones de las personas. Si bien tienen } \\
\text { definido un mapa de procesos, por ser requisito de la } \\
\text { ISO } 9001 \text {, este aún no está implementado en la orga- } \\
\text { nización (sólo se dispone de un manual de procesos } \\
\text { en desuso). Asimismo, no disponen de un organigrama } \\
\text { claro, se organizan por áreas y no hay comunicación } \\
\text { formal entre ellas. } \\
\text { El programa de mejora continua es una intención pero } \\
\text { son pocas las acciones logradas al momento, sólo se } \\
\text { realizan mejoras reactivas. No obstante la filosofía de } \\
\text { la dirección es siempre el de la mejora aunque no esté } \\
\text { formalizada. } \\
\text { En palabras de la responsable de recursos humanos } \\
\text { "El dueño transmite e induce que cada problema o } \\
\text { resultado negativo se debe analizar para no volver a } \\
\text { repetirlo". Por otro lado el jefe de producción señala } \\
\text { "Hay un nuevo compromiso, estamos realizando reunio- } \\
\text { nes serias entre todos nosotros para usar la Norma de } \\
\text { manera adecuada, analizando los problemas, buscando } \\
\text { la causa raíz, dejando asentado el problema y la } \\
\text { solución para que no vuelva a pasar", así como también } \\
\text { expresa "Estamos en camino a mejorar lo solicitado por } \\
\text { la Norma y las cosas se están haciendo a conciencia } \\
\text { para aprender del error". }\end{array}$ \\
\hline
\end{tabular}




\begin{tabular}{|c|c|c|c|}
\hline Gente & $\begin{array}{l}\text { El clima laboral observado, luego } \\
\text { de realizar la visita por la planta, se } \\
\text { percibe inadecuado, con falta de mo- } \\
\text { tivación en los empleados y descon- } \\
\text { fianza mutua. Además, la planta no } \\
\text { muestra adecuado orden y limpieza. } \\
\text { La empresa reconoce la diferencia } \\
\text { en el rendimiento operativo de sus } \\
\text { empleados, según la subjetividad del } \\
\text { jefe de planta, lo cual impacta en una } \\
\text { parte variable del salario que perci- } \\
\text { ben. En palabras del jefe de planta } \\
\text { "cada uno hace su trabajo". Se de- } \\
\text { duce que no se fomenta el trabajo en } \\
\text { equipo y la calidad es sólo mirada en } \\
\text { el producto terminado }\end{array}$ & $\begin{array}{l}\text { Ante la falta de definición y uso } \\
\text { de equipos interfuncionales, se } \\
\text { genera una aislación entre los } \\
\text { departamentos, haciendo que los } \\
\text { problemas detectados sean mane- } \\
\text { jados, en su mayoría, por el Ge- } \\
\text { rente General o el responsable de } \\
\text { la Gerencia Industrial. Si bien ante } \\
\text { ciertos problemas se generan con- } \\
\text { sultas con los expertos internos en } \\
\text { el tema, las decisiones frente a és- } \\
\text { tos siempre se centralizan en estas } \\
\text { dos personas. }\end{array}$ & $\begin{array}{l}\text { Los equipos de trabajo no están definidos formalmente } \\
\text { pero los mandos medios trabajan de forma relacionada, } \\
\text { interactuando con las TI y reuniones periódicas. El clima } \\
\text { de trabajo es muy bueno y la organización se visualiza } \\
\text { ordenada. } \\
\text { Las necesidades y dependencia de las funciones y los } \\
\text { clientes internos no están definidas, no hay delimitacio- } \\
\text { nes establecidas, como tampoco las responsabilidades } \\
\text { de cada uno. } \\
\text { Según la responsable de recursos humanos "La empre- } \\
\text { sa cuenta con muy buenos recursos humanos desde el } \\
\text { operario hasta los profesionales, pero no se trabaja en } \\
\text { formar aún más esos recursos. Por ejemplo si alguien } \\
\text { es bueno en lo técnico y se nota que le falta liderazgo } \\
\text { no se hace nada para subsanarlo". Reconocen que no } \\
\text { se atienden las necesidades del personal ni se aporta al } \\
\text { desarrollo de su desempeño, no se apuesta al desarrollo } \\
\text { de carrera. Se recluta por el conocimiento técnico y lue- } \\
\text { go no se aporta en el desarrollo de habilidades. Aunque } \\
\text { últimamente al elegir empleados están buscando valo- } \\
\text { res y responsabilidad, bajando el peso a la experiencia. } \\
\text { Luego capacitan mucho en aspectos técnicos. Pierden } \\
\text { algunos recursos humanos profesionales al enfrentarse } \\
\text { contra grandes industrias que ofrecen mejores benefi- } \\
\text { cios } \\
\text { Complementariamente, el jefe de producción expresa } \\
\text { "Estamos tratando de armar una evaluación de desem- } \\
\text { peño, crear objetivos por áreas y crear un desarrollo de } \\
\text { carrera". Además se señala que "Hay áreas mejor orga- } \\
\text { nizadas que otras que las define el líder de cada área, } \\
\text { por ejemplo Producción está muy bien pero Calidad no } \\
\text { aún. Calidad ahora depende del Gerente General y éste } \\
\text { le pidió en la última reunión al líder de calidad que defina } \\
\text { el objetivo para su área .... de a poco se va trabajando y } \\
\text { mejorando en la formalización". }\end{array}$ \\
\hline $\begin{array}{c}\text { Tecnologías } \\
\text { de la informa- } \\
\text { ción }\end{array}$ & $\begin{array}{l}\text { Utilizan un sistema de TI llamado } \\
\text { Tango 17, que tiene prestaciones } \\
\text { sobre facturación y control de inven- } \\
\text { tarios. Dicho sistema recientemente } \\
\text { se está comenzado a implementar. } \\
\text { De la entrevista se comprueba que } \\
\text { para el control de inventarios aún } \\
\text { no se utiliza este programa y se evi- } \\
\text { dencia además que aún no facilita la } \\
\text { integración de la información entre } \\
\text { áreas. }\end{array}$ & $\begin{array}{l}\text { Actualmente utilizan tres sistemas } \\
\text { de TI, Excel, Bejerman y Solomon. } \\
\text { El primero es usado en forma inde- } \\
\text { pendiente del último o como com- } \\
\text { plemento para bajar información y } \\
\text { poder analizarla. El segundo se uti- } \\
\text { liza para la liquidación de sueldos } \\
\text { y jornales. Por último, el software } \\
\text { Solomon es un sistema ERP que } \\
\text { adquirió la empresa en búsqueda } \\
\text { de una integración de las funcio- } \\
\text { nes de administración, cotización, } \\
\text { compras, depósito, producción y } \\
\text { mantenimiento. "No tiene aún bue- } \\
\text { nos resultados", según manifestó el } \\
\text { Gerente General. } \\
\text { La empresa no cuenta con un área } \\
\text { de TI que dé soporte a una integra- } \\
\text { ción interna, por lo que subcontrata } \\
\text { esta función a una empresa exter- } \\
\text { na. }\end{array}$ & $\begin{array}{l}\text { La empresa utiliza un sistema de TI especializado para } \\
\text { la industria metalmecánica llamado Strumis. El mismo } \\
\text { hace seguimiento de las piezas componentes del pro- } \\
\text { ducto, gestiona la compra de insumos necesarios, man- } \\
\text { tiene las distintas áreas comunicadas, maneja varios } \\
\text { proyectos simultáneamente, comparte con los clientes el } \\
\text { avance del pedido o proyecto por medio de este sistema. } \\
\text { Se integra con otros sistemas de TI como el software de } \\
\text { gestión administrativa Tango y el reloj. Además, están } \\
\text { diseñando un sistema de trazabilidad de las partes de } \\
\text { la estructura a través de un TAG (imán con información } \\
\text { ubicado en las piezas) que se acopla con Strumis. Este } \\
\text { software rescata información de manera automática } \\
\text { conformado un tablero semáforo que indica el avance } \\
\text { en producción. } \\
\text { Priorizan la integración de áreas al momento de selec- } \\
\text { cionar las TI pero no están formalizados los criterios } \\
\text { para las compras de TI. Los sistemas TI están integra- } \\
\text { dos internamente y parcialmente con los clientes, ya que } \\
\text { éstos pueden ver el avance de obra. } \\
\text { En palabras del jefe de producción "Antes usaba una } \\
\text { planilla de Excel para seguir el avance de obra, Ilego } \\
\text { un momento en que eso fue inmanejable, el número de } \\
\text { piezas es elevado. Ahora con el Strumis se facilitó el } \\
\text { proceso porque este programa toma los datos del Tecla } \\
\text { (que es donde está el despiece, y el modelo digitalizado } \\
\text { en } 3 D \text { ), y le da seguimiento a cada pieza, informa si la } \\
\text { materia prima está disponible, se realizan las órdenes de } \\
\text { compras por medio de este sistema, se puede dar segui- } \\
\text { miento por obra y varias simultáneamente, muestra por } \\
\text { medio de colores que se está soldando, que está hecho } \\
\text { y que está pendiente. Es una herramienta visual muy } \\
\text { potente. Estos informes se envian a los clientes. Esto ha } \\
\text { agilizado enormemente los tiempos". }\end{array}$ \\
\hline
\end{tabular}


Determinado el estado de situación actual y por tanto el nivel de madurez alcanzado para cada dimensión estudiada, se cuenta con un diagnóstico que sirve como herramienta para delinear acciones futuras con el propósito de mejorar el uso de recursos y su interacción, la ejecución y monitoreo de los procesos, el grado de aplicación de las herramientas disponibles y consecuentemente, lograr el ascenso a un estado de nivel de madurez sucesivo a la dimensión más alta alcanzada, Figura 2.

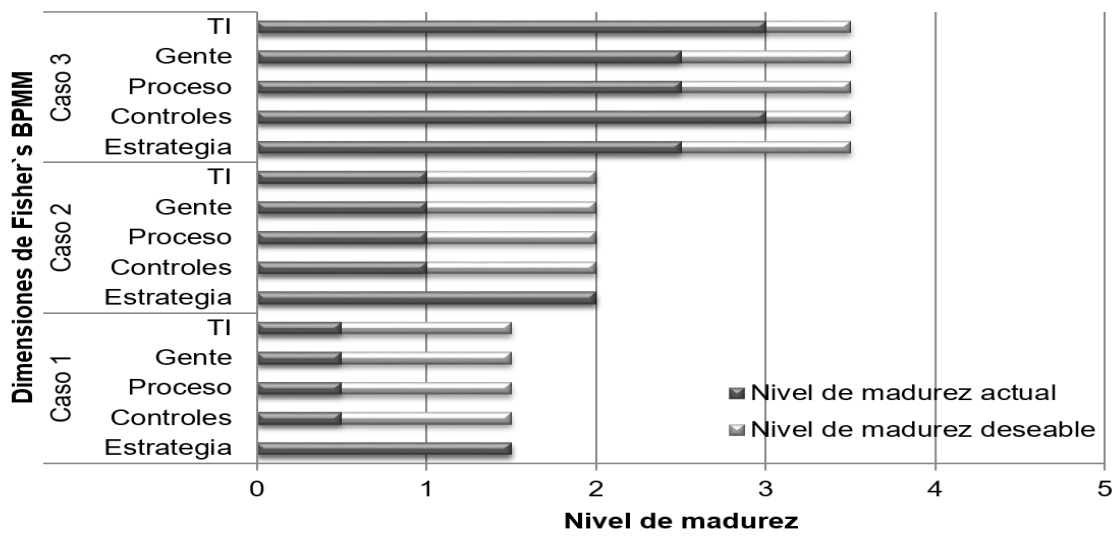

Figura 2. Nivel de madurez del sistema de gestión de procesos recomendado en cada empresa caso de estudio.

En la Tabla 2, se dispone un resumen del estado de situación actual de cada empresa caso de estudio y se brindan recomendaciones o lineamientos que permitan avanzar en el nivel de madurez del sistema de gestión de procesos de negocios.

Del análisis del diagnóstico obtenido se tiene indicio que las empresas que han avanzado en aplicación de principios o certificación de sistemas de gestión por normas, obtienen mayor nivel de madurez en el sistema de gestión de procesos de negocios.

Tal es la situación del caso 3 donde su calificación muestra mayor avance y madurez en todas las dimensiones analizadas y representa la organización que ha certificado el sistema de normas correspondiente a calidad ISO 9001:2015, se encuentra en desarrollo del sistema de gestión de seguridad y en menor grado de avance en el sistema de gestión medioambiental, y además, evidencia un enfoque por procesos parcialmente implantado al lograr una media de nivel de madurez igual a 2,7.

Contrariamente, el caso 1, el cual no ha indagado en aplicación de ningún sistema de gestión bajo normas, califica en valores inferiores en cada una de las dimensiones con una media en el nivel de madurez igual 0,7 . 


\begin{tabular}{|c|c|c|}
\hline Caso 1 & Caso 2 & Caso 3 \\
\hline $\begin{array}{l}\text { En este caso de estudio las palancas de cambio, } \\
\text { Ilamadas dimensiones, como son el control, los } \\
\text { procesos, gente y las tecnologías de la informa- } \\
\text { ción se encuentran en un nivel } 0.5 \text {, es decir no } \\
\text { completa el primer nivel Aislado; mientras que la } \\
\text { palanca estrategia, se halla en nivel } 1.5 \text {. } \\
\text { Esta empresa no aplica herramientas de gestión } \\
\text { y no ha logrado conocer sus procesos, mucho } \\
\text { menos medirlos y controlarlos. No procesa in- } \\
\text { formación para la toma de decisiones, como así } \\
\text { tampoco se apoya en el uso de TI. Su única for- } \\
\text { taleza radica en la característica emprendedora e } \\
\text { innovadora de su dueño. } \\
\text { Se recomienda que la PYME intente lograr una } \\
\text { alineación organizacional de las cinco dimensio- } \\
\text { nes, en principio, hasta el nivel } 1.5 \text {. Figura } 2 \text {. } \\
\text { Para ello, la PYME deberá comenzar por pro- } \\
\text { fesionalizar su personal en pos de lograr imple- } \\
\text { mentar herramientas de gestión. Para ello, puede } \\
\text { apoyarse en el uso de los principios de la Norma } \\
\text { ISO 9001 como soporte para avanzar en el nivel } \\
\text { de madurez de su sistema de gestión. } \\
\text { Las buenas ideas en desarrollo de producto que } \\
\text { consiguen deben apuntalarse con una gestión } \\
\text { que acompañe adecuadamente desde lo opera- } \\
\text { tivo, no sólo en producción sino en la integración } \\
\text { del resto de las áreas. }\end{array}$ & $\begin{array}{l}\text { En este caso de estudio las palancas de cambio, } \\
\text { como son el control, los procesos, gente y las } \\
\text { tecnologías de la información se encuentran en } \\
\text { un nivel } 1 \text { Aislado; mientras que la palanca estra- } \\
\text { tegia, se halla en nivel } 2 \text {, Integrada tácticamente. } \\
\text { Esto sugiere que la empresa ha comenzado el } \\
\text { esfuerzo de cruzar las áreas a través de la es- } \\
\text { trategia, pero la misma no es acompañada por el } \\
\text { resto de las dimensiones, que siguen trabajando } \\
\text { en islas funcionales en pos de mejorar la eficien- } \\
\text { cia con información y controles aislados. Lo an- } \\
\text { terior hace que las respuestas sean lentas a las } \\
\text { condiciones cambiantes del mercado. } \\
\text { Se recomienda que la PYME logre una alinea- } \\
\text { ción organizacional de las cinco dimensiones, en } \\
\text { principio, hasta el nivel } 2 \text { Integrado tácticamente. } \\
\text { Figura } 2 \text {. } \\
\text { Para ello, debe desarrollar un plan de acción que } \\
\text { se traduzca en beneficios relacionados con una } \\
\text { eficiencia cruzada entre áreas, un sistema que } \\
\text { potencie el nivel de integración de la información } \\
\text { y los estándares de procesos, la conformación de } \\
\text { equipos de trabajo, entre otros. Estos cambios } \\
\text { le van a permitir a la PYME tomar mejores de- } \\
\text { cisiones y a futuro seguir trabajando para lograr } \\
\text { niveles de madurez superiores en su sistema de } \\
\text { gestión, que la lleven a un alineamiento completo } \\
\text { de todos sus procesos para conseguir óptimos } \\
\text { resultados }\end{array}$ & $\begin{array}{l}\text { En este caso de estudio las palancas de cam- } \\
\text { bio, como son gente, procesos y estrategia se } \\
\text { encuentran en un nivel } 2.5 \text {, superando las carac- } \\
\text { terísticas del nivel Tácticamente integrado; mien- } \\
\text { tras que las palancas controles y las tecnologías } \\
\text { de la información se hallan en nivel } 3 \text {, Proceso } \\
\text { conducido. } \\
\text { Esta empresa cuenta con una estrategia explici- } \\
\text { ta pero no compartida, una sólida posición en el } \\
\text { mercado (aspira a ser líder a nivel nacional), y se } \\
\text { vislumbra un incipiente trabajo interfuncional y la } \\
\text { integración con algunos de sus clientes. } \\
\text { La empresa presenta una toma de decisiones } \\
\text { parcialmente descentralizadas, y la existencia de } \\
\text { métricas de procesos. } \\
\text { El enfoque de procesos está diseñado pero im- } \\
\text { plementado parcialmente. Asimismo, la filosofía } \\
\text { de mejora continua está débilmente presente, y } \\
\text { la resolución de problemas es reactiva, sin méto- } \\
\text { do que la respalde. } \\
\text { Existe un equipo de mandos medios en consoli- } \\
\text { dación, un cambio en los criterios de selección de } \\
\text { personal, un esfuerzo en su desarrollo de carrera, } \\
\text { y un área de Recursos Humanos para apuntalar } \\
\text { estos esfuerzos. } \\
\text { El uso de tecnología avanzada, la existencia de } \\
\text { diversas TI (de gestión administrativa, de produc- } \\
\text { ción, etc.) y la evidente integración entre sí es } \\
\text { valiosa, logrando traccionar la interfuncionalidad } \\
\text { entre áreas. } \\
\text { Se propone que la PYME logre una alineación } \\
\text { organizacional de las cinco dimensiones, hasta el } \\
\text { nivel } 3.5 \text {. Figura } 2 \text {. } \\
\text { Algunas potenciales acciones futuras recomen- } \\
\text { dadas consisten en: Formalizar y comunicar el } \\
\text { enfoque estratégico de la empresa, con el fin de } \\
\text { alinear los esfuerzos organizacionales. Avanzar } \\
\text { en la filosofía del enfoque de procesos y afianzar } \\
\text { su implementación recurriendo a los líderes de } \\
\text { procesos para que definan, implementen, mejo- } \\
\text { ren y mantengan los procesos clave del negocio. } \\
\text { Asegurar que los indicadores de desempeño de } \\
\text { proceso estén vinculados simultáneamente al } \\
\text { desempeño individual y de equipo. Consolidar los } \\
\text { sistemas TI para agilizar los procesos y la dispo- } \\
\text { sición de información para la gestión. }\end{array}$ \\
\hline
\end{tabular}

Por su parte el caso 2, con una media en el nivel de madurez igual a 1,2, evidencia aún una estructura por funciones con gran dependencia de la gerencia para la toma de decisiones, desarrollo de actividades, comunicación con clientes y proveedores y definición de acciones tanto estratégicas como operativas. Características que indican que la orientación a procesos no está establecida a pesar de poseer el certificado ISO 9001:2015.

En resumen, la situación actual del sistema de gestión de procesos de negocios, de las tres empresas estudiadas bajo el modelo de madurez de Fisher (2004) es: la empresa del Caso 1 está en la partida de este modelo de madurez, con casi nula aplicación de herramientas, muy poca profesionalización de sus empleados y desconocimiento total de sus procesos; el Caso 2 presenta un avance significativo en la capacidad y proceder de sus procesos, si bien aún no logran sistematizarlos; el Caso 3 evidencia logros relevantes en la aplicación del enfoque por procesos y en el uso de tecnología como soporte, sin embargo falta completar acciones para que sus procesos sean perfectamente conducidos.

Desde el análisis de Álvarez García et al. (2014), la empresa del caso 3 se encuentra en un estadio superior en su camino hacia la implementación de normas de calidad, emplea herramientas más evolucionadas vinculadas con la gestión de la calidad, que le permite 
alcanzar un mayor nivel de madurez en los factores críticos vinculados con liderazgo, política/ planificación de calidad, alianzas y recursos, gestión de empleados, aprendizaje, gestión de procesos y mejora continua. Esto se relaciona con el hecho que las empresas ya tienen un gran camino recorrido hacia el concepto de excelencia.

Asimismo, los resultados hallados están de acuerdo con Pérez Mergarejo et al. (2014) quienes opinan que las Normas ISO son de mayor uso en PYME. En el caso de la 9001, aunque no constituyen un modelo de madurez, puede ser considerada como un paso importante en la estandarización de procesos y la ISO 9004 puede ser empleada en la medición de la madurez. Recomiendan tomar en cuenta los requisitos de la Norma ISO 9001 como punto de partida para integrarlos al modelo de madurez de proceso de negocios.

Del mismo modo Britsch et al. (2012) busca diseñar procesos de negocio basados en un concepto de evaluación continua e integral. Sin embargo, aclaran que las PYME tienen requisitos especiales con respecto a los modelos de madurez debido a su tamaño y recursos limitados. En concordancia, McCormack et al. (2003) indica que la gestión por procesos aporta las bases necesarias para avanzar en el desarrollo de capacidades.

Por otro lado, el diagnóstico obtenido se usa para comprobar la hipótesis planteada, mediante una diferencia de medias para muestras independientes. La Figura 3 muestra la tabla ANOVA, obtenida como resultado de la prueba estadística t para muestras independientes, donde se considera como variable de clasificación al tipo de empresa, certificada y no certificada, y como variable dependiente los niveles de madurez alcanzados en las palancas de cambio (Estrategia, Controles, Proceso, Gente y TI) del modelo de Fisher (2004).

Proebs i para mosestras Indepesdientes

Figura 3. Tabla ANOVA del test t para muestras independientes.

En la Figura 3 se observa un $p$ - valor de 0,0051 obtenido en el análisis de la varianza (ANOVA). Esto denota, para un nivel de significancia de 0,05 , que existe evidencia significativa para rechazar la hipótesis nula planteada, donde se afirma que los niveles de madurez para organizaciones certificadas y no certificadas no presentan diferencia. Al rechazar esta hipótesis se acepta la hipótesis alternativa, la cual asevera que las organizaciones certificadas bajo ISO 9001:2015 alcanzan un mayor nivel de madurez.

Del análisis de los resultados previos se comprueba que el caso 3 alcanza mayores niveles de madurez en su sistema de gestión de procesos de negocios, siendo aquel que cuenta con una certificación en ISO 9001:2015 y exhibe el mayor avance en la implementación de una orientación a procesos. Esto ratifica la necesidad de una gestión por procesos establecida y da pautas que el uso de esta Norma es una fuente de ayuda y soporte, la cual podría ser una herramienta complementaria al modelo de madurez de proceso de negocios.

Tal como ha sido expresado por Heras et al. (2009) al inicio del proceso de implantación de un sistema de gestión de calidad se recurre al uso de herramientas simples, de propósito general y que no requieren de conocimiento técnico elevado. El caso 2 particulariza esta situación con una aplicación de herramientas generalizadas, lo cual no descubre ni mejora situaciones particulares por lo que no permite alcanzar altos niveles de madurez en su sistema de gestión. A partir de aquí, los modelos de madurez de sistemas de gestión de procesos de negocios podrían fomentar avances en este sentido. 
En este contexto los resultados de la investigación realizada por Figueiredo et al. (2014), quienes estudiaron las prácticas de gestión por procesos en un estudio de caso, indicaron que las prácticas relacionadas con los criterios Mapeo de Procesos e Indicadores se evaluaron positivamente. Mientras que Mejora de Procesos, Gerente de Procesos, Gestión de Personas y Liderazgo presentaron varias oportunidades de mejora.

Por su parte Ramos et al. (2019) describen las dificultades y beneficios al implantar una gestión por procesos. Las primeras fueron la falta de alineación entre los intereses estratégicos y operativos, el compromiso del proceso y su integración, y la resistencia al cambio. Los posibles beneficios fueron la reducción del retrabajo, la mejora de la calidad del producto, el aumento de la productividad y la gestión de riesgos.

En tanto los resultados de Raschke et al. (2010) comprueban que organizaciones con procesos de cumplimiento de pedidos y de compra más maduros parecen tener niveles más altos de resultados de procesos de calidad que aquellas con procesos menos maduros. Sugieren que el modelo de madurez del proceso de negocios proporciona un medio para comparar el progreso de las capacidades de la organización en relación con sus procesos.

Por consiguiente, los resultados expuestos aportan positivamente a la hipótesis planteada, de manera que organizaciones con sistema de gestión de calidad implantado bajo norma, resultan más maduras que aquellas con ausencia del mismo y ratifican la necesidad de una gestión por procesos establecida. Por tanto, se piensa que las normas de calidad como ISO 9001:2015, podrían ser una herramienta de ayuda para complementar el modelo de madurez de procesos de negocios y un uso eficiente de recursos.

Adicionalmente, Van Looy y Shafagatova (2016) insisten en el valor de mediciones bien fundamentadas para lograr una mejor conexión entre BPM y los modelos de madurez y consecuentemente elevar el rendimiento de la organización. Resaltan ser cuidadoso en la elección de indicadores de desempeño específicos que representen eficazmente el vínculo entre el desempeño real del proceso y el desempeño esperado del proceso.

En tanto los resultados de la investigación realizada por Škrinjar et al. (2013) han mostrado la importancia de la participación de la alta dirección, ser responsable de asegurar el ajuste entre la estrategia y contingencias en el entorno de una empresa y el nombramiento de propietarios de procesos para elevar los niveles de madurez BPO. Además, el ajuste de la tecnología a las tareas es realmente vital (relacionadas con la implementación de TI, por ejemplo gestión de la cadena de suministro, relación con el cliente, sistemas de gestión y BPM).

En concordancia Van Looy (2018) identificó vínculo positivo entre BPM y la innovación digital (DI) donde las organizaciones se apoyan en los factores de éxito de BPM para realizar la DI. Se revelaron obstáculos comunes, como resistencia de los empleados, poco apoyo de la alta dirección y problemas de alineación estratégica, aunque la DI se puede posicionar en una situación más estable mediante BPM.

Estas investigaciones dan indicio que para seguir avanzando en el nivel de madurez del sistema de gestión de procesos es buena elección recurrir al uso de indicadores cuidadosamente definidos y apoyados en la tecnología de la información y la innovación digital. En consonancia, el caso 3 manifiesta elevados resultados en las palancas de cambio controles y $\mathrm{TI}$ y, consiguientemente refleja el mayor nivel de madurez. 


\section{CONCLUSIONES}

Los resultados obtenidos en esta investigación aportan positivamente a la hipótesis planteada, las organizaciones estudiadas con un sistema de gestión de calidad implantado y certificado bajo norma ISO 9001:2015 resultan más maduras en su sistema de gestión de procesos de negocios que aquella con ausencia de los mismos.

Las acciones futuras propuestas pretenden actuar sobre el aumento en el nivel de madurez del sistema de gestión de procesos a través de desarrollar y fortalecer las capacidades de la organización y sistematizar los procesos.

Con el crecimiento en la madurez de los modelos de cada caso en estudio, los procesos de negocios se tornan eficientes y existe una guía para la toma de decisiones que apoyan programas y reformas estructurales, proporcionando ventajas competitivas para una empresa con influencia indirecta en el contexto social de la población de la ciudad donde están insertas estas empresas.

BPM con orientación a procesos proporciona a las organizaciones una guía sobre cómo obtener el control de sus procesos de negocio, evolucionando hacia una cultura de rendimiento y excelencia en la gestión. La mejora continua del proceso se basa tanto en pequeños pasos evolutivos como en las innovaciones de proceso.

Las investigaciones futuras deben continuar avanzando en la ejecución de las propuestas enmarcando el trabajo en una investigación - acción, donde tanto los docentes investigadores como los directivos y empleados operativos de la organización interactúan, trabajan de manera conjunta, contribuyen en la implementación de herramientas y por ende en el avance de la madurez de los procesos de negocios desarrollados en cada caso.

Se debe seguir trabajando para obtener más conocimiento de los factores que contribuyen y dificultan el uso exitoso de los modelos de madurez de negocios en la práctica, deseablemente con aumentar tamaño de muestra para reajustar y acomodar obstáculos de su uso en PYME.

\section{REFERENCIAS}

ÁlVAREZ GARCíA, J., VILA ALONSO, M., FRAIZ BREAC, J. A. y DEL RíO RAMAC, M. (2014). Relación entre herramientas y factores críticos de la calidad. Revista Europea de Dirección y Economía de la Empresa [en línea] 23, 82-97. Disponible en: http://dx.doi. org/10.1016/j.redee.2012.11.004

BRITSCH, J., BULANDER, R. y MORELLI, F. Evaluation of maturity models for business process management: Maturity models for small and medium-sized enterprises. En: Proceedings of the International Conference on Data Communication Networking, e-Business and Optical 
Communication Systems, ICE-B-2012. [en línea] pp. 180-186. Italia: SCITEPRESS (Science and Technology Publications, Lda). 2012. vol.1,. ISBN: 978-989-8565-23-5. Disponible en: http://dx.doi.org/10.5220/0004074701800186

DÍAZ JAIMES, M. y ORTIZ PIMIENTO, N. (2012). Revisión de Modelos de Madurez: Estrategia de Evaluación del Desempeño para Empresas de Manufactura. Revista UIS Ingeniería [en línea]. 11(1), 55-72. Disponible en: https://revistas.uis.edu.co/index.php/revistauisingenierias/ article/view/55-72

DUFFY, J. (2001). Maturity models: blueprints for evolution. Strategy Leadership [en línea] 29(6), 19-26. Disponible en: https://doi.org/10.1108/EUM0000000006530

PwCArgentina, 2019. Expectativas 2019 PYME en Argentina [en línea]. Argentina: $6^{\circ}$ Encuesta a PYME de PwC Argentina, 20 Disponible en: https://www.pwc.com.ar/es/publicaciones/ assets/expectativas-pymes-2019.pdf

FIGUEIREDO, M., LIMA, G., RODRIGUES, J., FILHO, D., HERKENHOFF, D., FIGUEIREDO, L. y FIGUEIREDO, C. Evaluation of the Business Process Management Practices: An Application in the Company of Oil and Gas Exploration and Production. En: Prado-Prado, J.C. y García-Arca, J. (eds.). Annals of Industrial Engineering Londres: Springer London, 2014, pp. 291-298.

FISHER, D. (2004). The business process maturity model: a practical approach for identifying opportunities for optimization. Bus. Process Trends [en línea]. 9(4),11-15 Disponible en: https:// www.bptrends.com/bpt/wp-content/publicationfiles/10-04\%20ART\%20BP\%20Maturity\%20 Model\%20-\%20Fisher.pdf

FRYT, M. (2019). Process Maturity Models - Applicabilityand Usability Review. World Scientific News [en línea].129, 51-71. . Disponible en: http://www.worldscientificnews.com/wp-content/ uploads/2019/04/WSN-129-2019-51-71.pdf

HERAS, I., MARIMON, F. y CASADESÚS, M. (2009). Impacto competitivo de las herramientas para la gestión de la calidad. Cuadernos de Economía y Dirección de la Empresa [en línea]. 12(41), 7-36. Disponible en: https://doi.org/10.1016/S1138-5758(09)70046-5

Informe Especial: Nivel de competencia directa entre PYME industriales [en línea]. Argentina: Fundación Observatorio PYME, 2019a Disponible en: http://www.observatoriopyme.org.ar/ project/competencia_directa_pyme/

Informe de Coyuntura de las PYME industriales, software y servicios informáticos. II Trimestre 2019 [en línea]. Argentina: Fundación Observatorio PYME, 2019b Disponible en: http://www. observatoriopyme.org.ar/newsite/wp- content/uploads/2019/10/Informe-Coyuntural-II-19.pdf

Informe Macro Región Centro [en línea]. Argentina: Fundación Observatorio PYME, 2015 Disponible en: http://www.observatoriopyme.org.ar/wp-content/uploads/2016/01/FOP MR 1508 Informe-Macro-Region-CENTRO-2015.pdf

LAHTI, M.; SHAMSUZZOHA, A. y HELO, P. (2009). Developing a maturity model for supply chain management. International Journal of Logistics System and Management [en línea]. 5(6), 654-678. Disponible en: https://doi.org/10.1504/IJLSM.2009.024796

Las PYME Argentinas. Contexto, diagnóstico y políticas necesarias [en línea]. Argentina: Confederación Argentina de la mediana empresa (CAME), 2017 Disponible en: http:// 
$\underline{\text { redcame.org.ar/adjuntos/PoliticasNecesariasParalmpulsaralasPymes.pdf }}$

LOCKAMY, III y MCCORMACK, K. (2004). The Development of a Supply Chain Management Process Maturity Model Using the Concepts of Business Process Orientation. Supply Chain Management: an Intenational Journal. [en línea]. 9(4), 272-278. Disponible en: http://dx.doi. org/10.1108/13598540410550019

MCCORMACK, K., JOHNSON, W. y WITH WALKER, W. Supply chain networks and business process orientation: advanced strategies and best practices. 2003. CRC Press LLC. APICS series on resource management. ISBN 1-57444-327-5.

MORADI MOGHADAM, M., SAFARI, H. y MALEKI, M. (2013). A novel model for business process maturity assessment through combining maturity models with EFQM and ISO 9004:2009. International Journal Business Process Integration and Management [en línea]. 6 (2), 167-184. Disponible en: http://dx.doi.org/10.1504/IJBPIM.2013.054680

MARTÍN NAVARRO, A., LECHUGA SANCHO, M. y MEDINA GARRIDO, J. (2018). BPMS para la gestión: una revisión sistemática de la literatura. Revista Española de Documentación Científica [en línea]. 41(3), e213. Disponible en: https://doi.org/10.3989/redc.2018.3.1532

PÁEZ, G., ROHVEIN, C., PARAVIE, D. y JAUREGUIBERRY, M. (2018). Revisión de modelos de madurez en la gestión de los procesos de negocios. Ingeniare, Revista chilena de ingeniería [en línea]. 26(4), 685-698. Disponible en: http://dx.doi.org/10.4067/S071833052018000400685

PÉREZ MERGAREJO, E., PÉREZ VERGARA, I. y RODRÍGUEZ RUÍZ, Y. (2014). Ingeniería Industrial v. XXXV, n.2, pp. 149-160.

RAMOS, K., MONTEZANO, L., LEAL DA COSTA JÚNIOR, R.y ALVES DE MEDEIROS SILVA, A. (2019). Dificuldades e benefícios da implantação da gestão de processos em organização pública federal sob a ótica dos servidores. Revista Gestão \& Tecnologia Pedro Leopoldo [en línea]. 19(4), 188-213,. Disponible en: http://dx.doi.org/10.20397/2177-6652/2019.v19i4.1593

RASCHKE, R. y INGRAHAM L. Business Process Maturity's Effect on Performance. En: Proceedings of the Sixteenth Americas Conference on Information Systems AMCIS 2010, Lima, Peru, 2010.

RÖGLINGER, M., PÖPPELBUß, J. y BECKER, J. (2012). Maturity models in business process management. Business Process Management Journal [en línea]. 18(2), 328-346. Disponible en: http://dx.doi.org/10.1108/14637151211225225

SIQUEIRA, J. O Modelo de Maturidade de Processos: como maximizar o retorno dos investimentos em melhoria da qualidade e produtividade. Em: Actas de ABM Congress Quality And Institutional Development Manager, Belo Horizonte: Instituto Brasileiro da Qualidade Nuclear, 2005.

ŠKRINJAR, R. y TRKMAN, P. (2013). Increasing process orientation with business process management: Critical practices, International Journal of Information Management [en línea]. 33(1), 48-60, Disponible en: https://doi.org/10.1016/j.ijinfomgt.2012.05.011

TARHAN A., TURETKEN O. y REIJERS, H. (2016). Business process maturity models: A systematic literature review. Information and Software Technology [en línea]. 75,122-134. Disponible en: https://doi.org/10.1016/j.infsof.2016.01.010 
TRKMAN, P. (2010). The critical success factors of business process management. International Journal of Information Management [en línea]. 30(2), 125-134. Disponible en: http://dx.doi.org/10.1016/j.ijinfomgt.2009.07.003

VAN LOOY A. On the Synergies Between Business Process Management and Digital Innovation. En: Weske, M., Montali, M., Weber, I., vom Brocke, J. (eds) Business Process Management. BPM 2018. Lecture Notes in Computer Science, 2018, Vol. 11080. Springer, Switzerland. ISBN: 978-3-319-98647-0. Disponible en: http://dx.doi.org/10.1007/978-3-31998648-7_21

VAN LOOY, A., SHAFAGATOVA, A. (2016). Business process performance measurement: a structured literature review of indicators, measures and metrics. SpringerPlus [en línea]. 5(1797), 1-24. Disponible en: http://dx.doi.org/10.1186/s40064-016-3498-1

WHEELEN T.y HUNGER J. Administración estratégica y política de negocios. Décima edición. México: Pearson Education, 2007. ISBN: 978-970-26-0878-3.

YIN, R. Case study research: design and methods. 5th ed. Thousand Oaks, CA, US: Sage Publication, Inc, 2014. ISBN 978-1-4522-4256-9.

Anexo 1: Modelo de madurez de Fisher (Fisher, 2004).

\begin{tabular}{|c|c|c|c|c|c|c|}
\hline & & Aislado & $\begin{array}{l}\text { Integrado } \\
\text { tácticamente }\end{array}$ & $\begin{array}{l}\text { Proceso } \\
\text { conducido }\end{array}$ & $\begin{array}{l}\text { Empresa } \\
\text { optimizada }\end{array}$ & $\begin{array}{l}\text { Red Operativa } \\
\text { Inteligente }\end{array}$ \\
\hline \multirow{3}{*}{ Estrategia } & \multirow{2}{*}{$\begin{array}{l}1.1 \\
1.2\end{array}$} & $\begin{array}{l}\text { Reactivo a las } \\
\text { condiciones del } \\
\text { mercado en 1-2 } \\
\text { años, típicamente } \\
\text { persiguiendo a un } \\
\text { competidor. }\end{array}$ & $\begin{array}{l}\text { Adaptar / reaccionar } \\
\text { a la dinámica del } \\
\text { mercado en un plazo } \\
\text { de } 12 \text { meses. }\end{array}$ & $\begin{array}{l}\text { Adaptar / } \\
\text { reaccionar a la } \\
\text { dinámica del } \\
\text { mercado dentro de } \\
\text { 3-6 meses. }\end{array}$ & \multirow{2}{*}{$\begin{array}{l}\begin{array}{l}\text { Adaptable a la } \\
\text { dinámica del } \\
\text { mercado dentro de } \\
\text { semanas. }\end{array} \\
\text { Empresa organizada } \\
\text { completamente en } \\
\text { torno a los procesos } \\
\text { (Gerencia por } \\
\text { Procesos). }\end{array}$} & \multirow{2}{*}{$\begin{array}{l}\text { Capacidad predictiva } \\
\text { y liderazgo } \\
\text { de mercado. } \\
\text { Continuamente } \\
\text { adaptable a la } \\
\text { dinámica del } \\
\text { mercado en tiempo } \\
\text { casi real. } \\
\text { La empresa y sus } \\
\text { partes interesadas } \\
\text { están organizados en } \\
\text { torno a los procesos. }\end{array}$} \\
\hline & & $\begin{array}{l}\text { Integración dentro de } \\
\text { las funciones. }\end{array}$ & $\begin{array}{l}\text { Alguna integración } \\
\text { interfuncional para } \\
\text { resolver problemas. }\end{array}$ & $\begin{array}{l}\text { Se establece una } \\
\text { organizacion inicial } \\
\text { de procesos a } \\
\text { nivel de toda la } \\
\text { empresa. }\end{array}$ & & \\
\hline & \multirow[t]{2}{*}{1.3} & $\begin{array}{l}\text { Las funciones estan } \\
\text { Impulsadas por } \\
\text { costos y eficiencia } \\
\text { locales. }\end{array}$ & $\begin{array}{l}\text { Integración inicial } \\
\text { con proveedores en } \\
\text { contacto uno a uno. }\end{array}$ & $\begin{array}{l}\text { Los procesos } \\
\text { de negocios } \\
\text { son el elemento } \\
\text { fundamental de la } \\
\text { empresa. }\end{array}$ & $\begin{array}{l}\text { La ejecución } \\
\text { de procesos } \\
\text { optimizados } \\
\text { generan una ventaja } \\
\text { competitiva. }\end{array}$ & $\begin{array}{l}\text { La ventaja } \\
\text { competitiva es } \\
\text { impulsada y } \\
\text { compartida con las } \\
\text { partes interesadas. }\end{array}$ \\
\hline \multirow[b]{2}{*}{ Controles } & & $\begin{array}{l}\text { Autoridad / } \\
\text { autonomía local y } \\
\text { funcional. }\end{array}$ & $\begin{array}{l}\text { Existencia de } \\
\text { una estructura de } \\
\text { administración } \\
\text { jerárquica. Decisiones } \\
\text { a nivel funcional } \\
\text { independientes. }\end{array}$ & $\begin{array}{l}\text { El lider formal de } \\
\text { proceso establece } \\
\text { las prioridades. } \\
\text { Businness case } \\
\text { direccionan los } \\
\text { proyectos. }\end{array}$ & $\begin{array}{l}\text { Equipos de } \\
\text { procesos } \\
\text { responsables del } \\
\text { desempeño general. }\end{array}$ & $\begin{array}{l}\text { Equipos de procesos } \\
\text { interempresariales } \\
\text { son responsables de } \\
\text { su propio desempeño }\end{array}$ \\
\hline & 2.2 & $\begin{array}{l}\text { No existen } \\
\text { normativas ni } \\
\text { directivas para el } \\
\text { uso de TI. No existe } \\
\text { programa formal de } \\
\text { evaluación de valor } \\
\text { de sistema de TI. }\end{array}$ & $\begin{array}{l}\text { Normativas y directivas } \\
\text { limitadas porque no } \\
\text { contemplan todo el } \\
\text { ancho de los procesos. }\end{array}$ & $\begin{array}{l}\text { Indicadores de } \\
\text { desempeño de } \\
\text { proceso vinculados } \\
\text { al desempeño } \\
\text { individual y de } \\
\text { equipo. }\end{array}$ & $\begin{array}{l}\text { Indicadores de } \\
\text { desempeño } \\
\text { relevantes } \\
\text { de procesos } \\
\text { formalizados como } \\
\text { las principales } \\
\text { medidas de } \\
\text { desempeño. }\end{array}$ & $\begin{array}{l}\text { Se usan indicadores } \\
\text { de desempeño de } \\
\text { procesos relevantes } \\
\text { para medir el } \\
\text { desempeño de } \\
\text { forma bidireccional } \\
\text { considerando las } \\
\text { partes interesadas. }\end{array}$ \\
\hline
\end{tabular}




\begin{tabular}{|c|c|c|c|c|c|c|}
\hline Proceso & 3 & $\begin{array}{l}\text { Procesos de negocio } \\
\text { estáticos. Aislados } \\
\text { funcionalmente y } \\
\text { geográficamente. } \\
\text { Enfoque funcional. } \\
\text { Comunicación } \\
\text { informal dentro de } \\
\text { los departamentos. }\end{array}$ & $\begin{array}{l}\text { Limitado uso de } \\
\text { reingenieria de } \\
\text { procesos y de } \\
\text { coordinación } \\
\text { entre funciones } \\
\text { (esfuerzos manuales } \\
\text { y al momento de } \\
\text { la necesidad). } \\
\text { Los sistemas de } \\
\text { TI direccionan las } \\
\text { definiciones básicas de } \\
\text { procesos. }\end{array}$ & $\begin{array}{l}\text { Transición } \\
\text { completa del } \\
\text { enfoque funcional } \\
\text { al enfoque } \\
\text { de proceso, } \\
\text { incluyendo } \\
\text { estructura de } \\
\text { gestión, equipos } \\
\text { de ejecución y } \\
\text { evaluación de } \\
\text { desempeño. } \\
\text { Orientación } \\
\text { hacia el BPO } \\
\text { (bussines process } \\
\text { outsourcing). }\end{array}$ & $\begin{array}{l}\text { Integración total } \\
\text { de procesos } \\
\text { en la empresa. } \\
\text { Compromiso con } \\
\text { el programa de } \\
\text { mejora continua } \\
\text { de procesos. } \\
\text { Outsourcing de } \\
\text { los procesos } \\
\text { empresariales no } \\
\text { básicos (reducir } \\
\text { costos y aumentar la } \\
\text { calidad) }\end{array}$ & $\begin{array}{l}\text { Integración total del } \\
\text { proceso a través } \\
\text { del ecosistema. } \\
\text { Los procesos clave } \\
\text { tienen un desempeño } \\
\text { optimo y se articulan } \\
\text { muy bien con las } \\
\text { partes interesadas } \\
\text { externas. }\end{array}$ \\
\hline Gente & 4 & $\begin{array}{l}\text { Los asuntos } \\
\text { importantes son } \\
\text { dominio de los } \\
\text { expertos. La } \\
\text { cultura es adversa, } \\
\text { desconfianza } \\
\text { mutua. No hay } \\
\text { procedimientos } \\
\text { formales de gestión } \\
\text { del cambio. Haré } \\
\text { mi trabajo, tú haces } \\
\text { el tuyo. }\end{array}$ & $\begin{array}{l}\text { Equipos } \\
\text { interfuncionales } \\
\text { (generalmente } \\
\text { soportados por TI). } \\
\text { Comprensión limitada } \\
\text { de necesidades y } \\
\text { dependencia entre las } \\
\text { funciones. }\end{array}$ & $\begin{array}{l}\text { Los líderes de } \\
\text { procesos definen, } \\
\text { implementan, } \\
\text { mejoran y } \\
\text { mantienen los } \\
\text { procesos clave. } \\
\text { Los equipos se } \\
\text { enfocan en la } \\
\text { ejecución con alta } \\
\text { calidad. }\end{array}$ & $\begin{array}{l}\text { Organización lean } \\
\text { enfocada a optimizar } \\
\text { las definiciones } \\
\text { de procesos y } \\
\text { la ejecución. } \\
\text { Capacitación } \\
\text { continua de } \\
\text { procesos para los } \\
\text { empleados. }\end{array}$ & $\begin{array}{l}\text { La selección de } \\
\text { proveedores y } \\
\text { clientes incluye } \\
\text { procesos y } \\
\text { atributos culturales. } \\
\text { Capacitación } \\
\text { continua de } \\
\text { procesos para los } \\
\text { empleados, clientes y } \\
\text { proveedores. }\end{array}$ \\
\hline $\begin{array}{c}\text { Tecnologías } \\
\text { de } \\
\text { Información }\end{array}$ & 5 & $\begin{array}{l}\text { Sistemas } \\
\text { independientes e } \\
\text { incomunicados. } \\
\text { Integración sólo } \\
\text { dentro de las } \\
\text { funciones. Sistemas } \\
\text { empresariales } \\
\text { heredados. }\end{array}$ & $\begin{array}{l}\text { Uso de sistema } \\
\text { ERP para apalancar } \\
\text { la integración } \\
\text { interfuncional. } \\
\text { Integración con } \\
\text { proveedores punto a } \\
\text { punto. El equipo de } \\
\text { TI lidera las iniciativas } \\
\text { multifuncionales } \\
\text { (sistemas enfocados). }\end{array}$ & $\begin{array}{l}\text { El equipo de TI } \\
\text { apoya al lider } \\
\text { del proceso. } \\
\text { Consolidación } \\
\text { de sistemas para } \\
\text { agilizar procesos e } \\
\text { información para la } \\
\text { gestión. }\end{array}$ & $\begin{array}{l}\text { Utiliza soluciones de } \\
\text { gestión de procesos } \\
\text { de negocio (BPM) } \\
\text { para automatizar } \\
\text { la ejecución, } \\
\text { supervisión y control } \\
\text { de procesos en toda } \\
\text { la empresa. }\end{array}$ & $\begin{array}{l}\text { Utiliza soluciones de } \\
\text { gestión de procesos } \\
\text { de negocio (BPM) } \\
\text { para automatizar y } \\
\text { controlar la ejecución } \\
\text { de procesos en todo } \\
\text { el ecosistema. }\end{array}$ \\
\hline
\end{tabular}

\section{Anexo 2: Cuestionario}

1. Descripción de la historia de la empresa desde su comienzo. ¿En qué situación se encuentra actualmente?

2. Información detallada de los productos y mercados actuales.

3. ¿La empresa tiene establecida su misión, visión y objetivos? (1.1) ¿Cómo es el mercado en el cual compite? ¿Cómo afecta a su negocio? (1.1)

4. ¿Cuáles son los objetivos de la empresa a mediano y largo plazo? ¿Están definidos formalmente? (1.1)

5. ¿Con qué frecuencia se definen los objetivos estratégicos y las estrategias? (1.1) Se revisa su cumplimiento, cómo?

6. ¿Qué tipo de estrategia sigue la organización? (¿deliberada o emergente?) ¿Está definida formalmente? (1.1) (1.3) (ej.: penetración en el mercado actual, inserción en nuevos mercados con nuevos productos, etc.)

7. ¿La estrategia de negocios se utiliza como base para definir las estrategias funcionales de los distintas funciones/procesos para lograr el objetivo? (1.2) (pedir un ejemplo)

8. ¿Quiénes se involucran en la implementación de las estrategias dentro de la empresa? (1.2)

9. ¿Se comunica la estrategia, los objetivos y resultados a los empleados? ¿A quiénes? ¿De 
qué manera y con qué frecuencia? ¿Se permite una retroalimentación en la comunicación?

A través de la observación y charlas percibir la estructura de comunicación (Carteleras, cuadros de gestión visual, mail, planillas para comunicar desde TI) (1.2)

10. ¿Cómo está estructurada la organización? (1.2) (1.3) (2.1) (3) (4) (funcional, interfucional, de procesos, por procesos y con partes interesadas) Pedir organigrama (si certificó ISO 9001 consultar documentos del SGC)

11. ¿Cuál es la ventaja competitiva de la empresa? ¿Cómo la estructura impacta en la ventaja competitiva? (1.3)

12. ¿Existen indicadores, cuáles? ¿Son parte de un sistema formal y son compartidos con otras funciones/personas (internas o externas)? (2.2) Chequear: Financieros: cash flow, ventas, ventas con respecto al año anterior y a la inflación; $\mathrm{RRHH}$ : ausentismo (accidentes laborales, enfermedad, problemas personales y licencias); Porcentajes del incremento del gasto de la empresa en sueldos y cargas sociales con respecto al año anterior; Seguridad e higiene: gente (relevamiento de USO de EPP) y eventos de inseguridad; Producción: toneladas elaboradas y procesadas en el taller; etc.

13. ¿Utilizan sistemáticamente indicadores financieros o no financieros y cuáles son los más importantes para usted? (Presidente) ¿Se hace un análisis global de todos los indicadores, como impactan unos con otros, cada cuanto se hace.? Ejemplos. (2.2)

14. ¿Cuál es el alcance de la medición de los indicadores? ¿Se procesan datos externos? (2.2)

15. ¿Cómo y quién definen los indicadores? ¿Cómo los crean, tienen un procedimiento, lo ayudan para su diseño o selección? ¿Involucran a clientes/ proveedores? (2.2)

16. ¿Cómo se obtienen y almacenan los datos? (2.2) (Ahondar cómo se recopila la información y si hay responsables definidos para hacerlo ¿cómo lo hacen? tienen una persona encargada de eso? es manual? cada cuánto?) (2.2)

17. ¿Cómo se realiza el análisis e interpretación de indicadores financieros y no financieros? ¿Utiliza sistemas de TI? ¿Cuáles? (¿Se los comparan con los objetivos planteados, se analizan las causas de desviación en el caso de que no se cumpla con el objetivo, quién es el responsable del análisis?) (2.2)

18. ¿Para qué usan los indicadores? (2.2) ¿Se los utiliza para acordar las recompensas? (4) Detalles, qué indicador usan para las recompensas por ejemplo y para quienes están destinadas (qué niveles operativo, gerencial, todos)

19. ¿Cómo percibe la influencia de los indicadores en el comportamiento de las personas/ proveedores/clientes/partes interesadas? (Direccionan los esfuerzos hacia las acciones, relación causa-efecto) (4)

20. ¿Se hace revisión de los indicadores, cómo se realiza, con qué frecuencia y quién se involucra? (2.2) (3)

21. ¿Cómo definen los requisitos de compras para los sistemas de TI? A la hora de comprar, ¿tienen en cuenta la articulación con otros sistemas de TI? ¿Cómo se define el uso de los sistemas de TI? (Quién tiene acceso y puede usarlo, transacciones habilitadas) (2.2) (5)

22. ¿Existen sistemas heredados? ¿Existe ERP, que módulos utilizan? (5)

23. ¿Los sistemas de TI están integrados interna y/o externamente? ¿Con quiénes? (5)

24. ¿Cómo es la difusión de la información de desempeño (financiero y no financiero) y sus 
metas? ¿Con qué frecuencia se actualizan los datos? (5) (Formato: manual, electrónico; uso de sistemas de $\mathrm{TI})$.

25. ¿Cómo es el clima de trabajo? ¿Existen formalmente equipos de trabajos, cuáles?, quienes se involucran (4)

26. ¿Se conforman por procesos /por proyectos? ¿Utilizan alguna TI para dar soporte a estas actividades? ¿Cómo se manejan los cambios? (3) (4) ¿Involucran personas de otras funciones?

27. Enfoque de procesos: pedir por ejemplo mapa de procesos, identificación de todos los procesos de la empresa, definición formal de clientes internos y externos (3)

28. ¿Están definidos formalmente los clientes y proveedores internos de cada proceso? (3)

29. ¿Cómo se resuelven problemas que involucran más de un área? (1.3) (2.1) (3) (4)

30. ¿Dónde comienza y termina su responsabilidad? (para Gerentes) ¿Cuál es su responsabilidad sobre el desempeño del proceso? (2.1) (3) (hacer foco en el uso de indicadores para controlar los procesos)

31. ¿Cuál es la importancia de la calidad para el desempeño de procesos? ¿La filosofía de calidad es importante para los lideres de proceso?(4)

32. ¿Se hace capacitación de personal, cliente y/o proveedores? ¿De qué tipo? (4)

33. ¿Existe integración con proveedores y/o partes interesadas? (1.3) (3)

34. ¿Existe un interés de integración con proveedores? ¿Existen acciones en ese sentido? cuáles? ¿Cuál es el objetivo de hacer la integración? (3)

35. ¿Se hace selección de proveedores y clientes? ¿Cuáles son los criterios? (4)

36. Programa de mejora continua: Pedir ejemplos concretos para definir si las mejoras son de tipo reactiva o proactiva. ¿Utilizan indicadores para hacer un seguimiento a la implementación de la mejora continua? (3) (4)

37. Organización lean visualmente (orden, stock, desperdicios, transporte) (4) 